\title{
Sport medicine and safety at work
}

\author{
Paola V. Gigliotti (1,2), Alexander Piratinskij (4), Saadsaoud Foued (5), Igor \\ Diemberger (6), Rezhna Adil Rasheed (7), Giorgio Fanò-Illic (8,9,10), Francesco \\ Coscia $(1,3)$
}

(1) Department of Medicine, University of Perugia, Ospedale "Santa Maria della Misericordia", Italy; (2) Laboratory of Sport Physiology, San Candido-Innichen, Italy; (3) Servizio Provinciale di Medicina dello Sport Ospedale Brunico-Bruneck e San CandidoInnichen, Italy; (4) The Ural Federal University, Ekaterinburg, Russia; (5) Universite de Msila, Algerie; (6) Institute of Cardiology, University of Bologna, Azienda Ospedaliera S. OrsolaMalpighi, Italy; (7) Erbil Polytechnic University, Kurdistan - Iraq (8) IIM-Interuniversity Institute of Myology; (9) A\&C M-C Foundation for Translational Myology, Padova; Italy; (10) Free University of Alcatraz, Santa Cristina di Gubbio, Italy

This article is distributed under the terms of the Creative Commons Attribution Noncommercial License (CC BY-NC 4.0) which permits any noncommercial use, distribution, and reproduction in any medium, provided the original author(s) and source are credited.

\begin{abstract}
As humans become more and more sedentary, physical capacities also become lost along with aerobic fitness, muscular strength, coordination, and action-reaction time. This situation can lead to not only absence from work (back pain is the most common reason in European Union (EU), but especially, workplace accidents. In this article we want to combine our experience with exercise physiology and physical capacities with our medical work in a critical environment. We tested over ten years, the fitness profile of 1200 Italian Alpine Soldiers, and gave them a scientific training program. We obtained a trained and homogeneous team (homogeneous, in terms of aerobic and anaerobic fitness). Here, we detail changes to aerobic and anaerobic fitness that occurred as a result of soldiers' participation in a training program. We consider this method necessary for safe work in a critical environment.
\end{abstract}

Key Words: fitness profile, critical environment, homogeneous team, training

Eur J Transl Myol 30 (1): xx1-xx4, 2020

The critical environment in an alpine setting may induce stressful changes of the physiological conditions of people that require emergency assistance. Factors which lead to the establishment of this environment, include both intrinsic morphological or geographical peculiarities, as well as extrinsic peculiarities (caused by human presence or human behavior). These changes are unrelated to the injuries caused by the event.

In particular:

1. The low temperature is an intrinsic critical peculiarity of mountain areas or waters.

2. The decrease of air oxygen is an intrinsic critical peculiarity of mountainous areas above 2300 meters, which becomes extreme above 4000 meters. Equally air dryness and sun irradiation are important factors to be taken into consideration.

3. Configuration of caverns is an intrinsic morphological peculiarity that may require emergency aid to be administered in very small and deep areas and for prolonged period of time, i.e., for several days.

4. War theatres have extrinsic critical peculiarities, caused by men facing each other. These extrinsic critical peculiarities often add critical peculiarities to environment.

5. Environment could unexpectedly become critical due to many factors, i.e., natural events, like earthquakes and landslides or terrorism.

During emergency work it is necessary to ensure the safety of a team of soldiers who have been sent to work in a critical environment. In this environment, the high and homogeneous physical capacities of the team means greater safety. In this study, a cohort of 1200 Italian Alpine soldiers were physically examined periodically over 10 years. This involved taking blood tests, electrocardiogram (ECG) and quantifying their fitness profile in accordance with the guidelines of the American College of Sports Medicine. ${ }^{1}$ These measurements were 


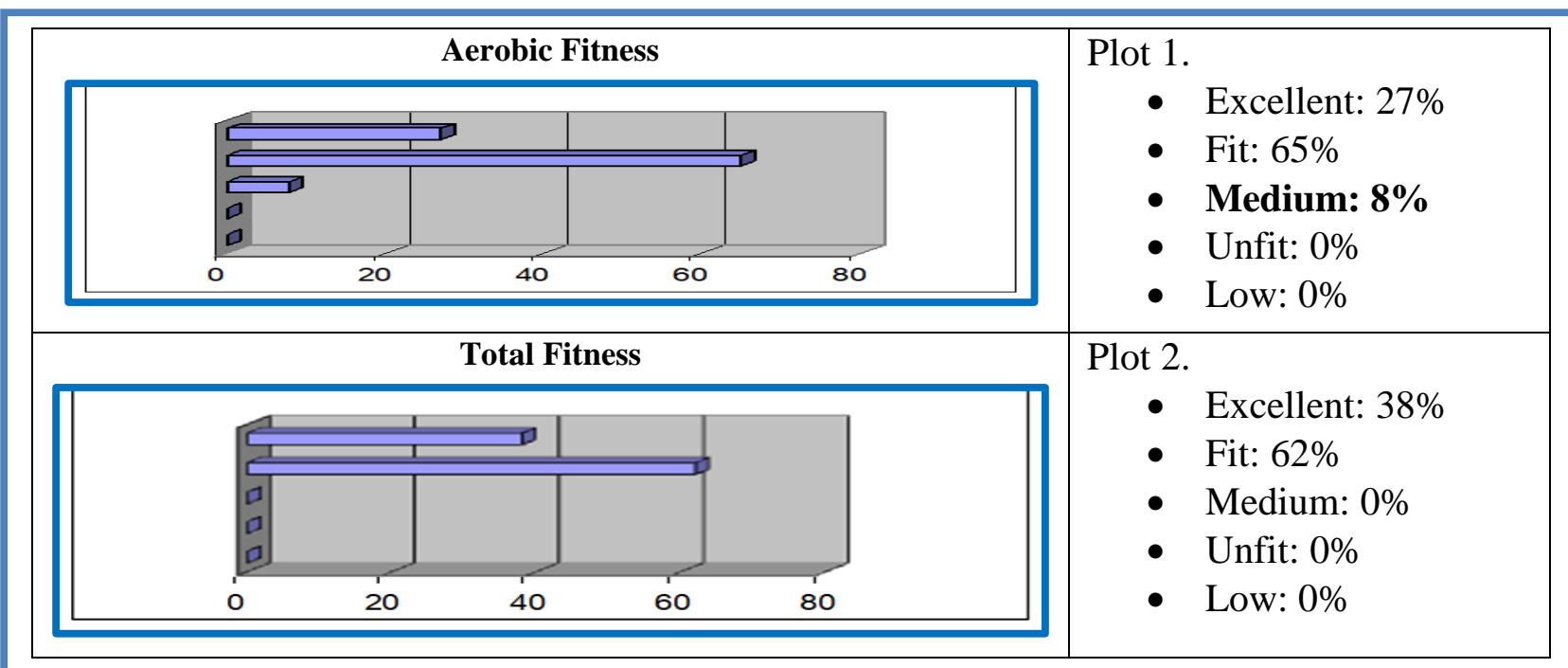

Fig. 1. Aerobic Fitness and Total Fitness before training. The physical capacities of the group are mainly fit, i.e., they have excellent or fit aerobic fitness; plot 2, but some subjects have medium aerobic fitness, plot 1.

taken in order to prescribe personalized training program to increase performance of soldiers in their mountain sports or their work in critical environment.

Fitness Levels: Aerobic and Total Fitness are presented in Figure 1 and 2. Aerobic fitness was measured before and after the training protocol. The aerobic fitness and total fitness shown in Figure 2 was taken after the training protocol, at the Torino Olympic Games in 2006 (Alpines Troup Programs). Both aerobic and total fitness increased, as seen in comparing the plot 3 of Figure 2 (before) with plot 4 of Figure 2 (after).

The power of the biceps muscle was also quantified, as a measurement of anaerobic capacity. In figure 3, most subjects were excellent or fit but not homogeneous. In figure 4, most subjects are excellent; demonstrating homogeneous anaerobic fitness across the group. During the CaSTA International Alpine Troup Championships, we also evaluated the hydration-dehydration levels of the competitors using the Impedance method, as a marker of acute fatigue. Results showed that there was a good level of hydration (54+/- $6 \%$ total body water) during a hard and prolonged physical exercise (two days of Patrol competitions: mountaineering ski and biathlon) which occurred in a hostile environment (winter mountain 1800-2200 meters, one part of the competition being held in the night). The temperature is between $-5 /-15$ degrees) after the specific training and specific diet program (hydration before, during and after the physical exercise). ${ }^{2,3}$

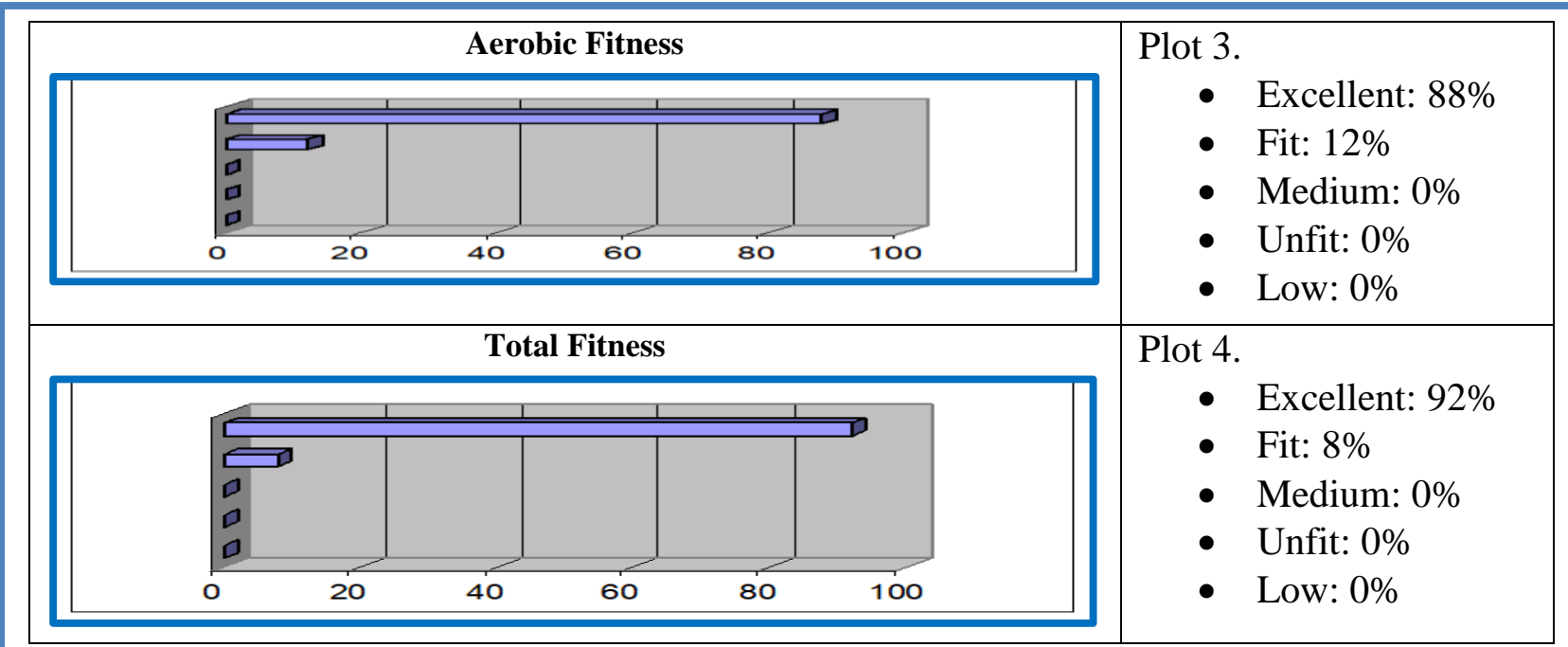

Fig. 2. Aerobic Fitness and Total Fitness (after training). The physical capacities of the group are all fit (i.e., have excellent or fit aerobic fitness; plot 1). In comparison to plot 2 of table 1, total fitness also increased with most subjects having excellent total fitness. 


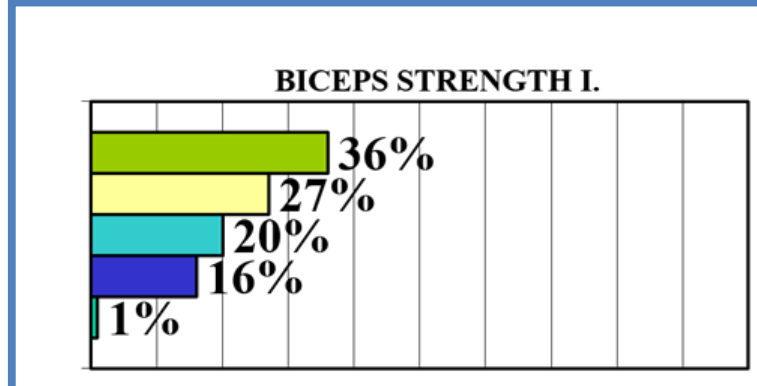

Fig 3. Muscle strength before training (biceps strength I).

From our study, we came to the following conclusions regarding aerobic and anaerobic fitness of the subjects.

\section{Aerobic fitness}

Having a good level of aerobic fitness means endurance capacity for prolonged exercise, quicker response time, lower levels of physical fatigue (improved oxygen levels in all organs and systems). Good flexibility, good joint mobility and well distributed muscular strength ensure a well-balanced distribution of weight without placing unnecessary strain on the joints. Aerobic training guarantees a control of body weight without restrictive diets; increases the levels of endorphins and consequently improves the team mood. In our study, we demonstrated that the training protocol undertaken increased aerobic fitness across our subjects, with respect to the ACSM guidelines.

\section{Anaerobic fitness}

High level of anaerobic fitness means capacity during intense and short duration exercise; this permits one to have "energy reserves" and a greater margin of safety. In a critical environment this means that the team is ready in case of weather changes or other hostile situations. In

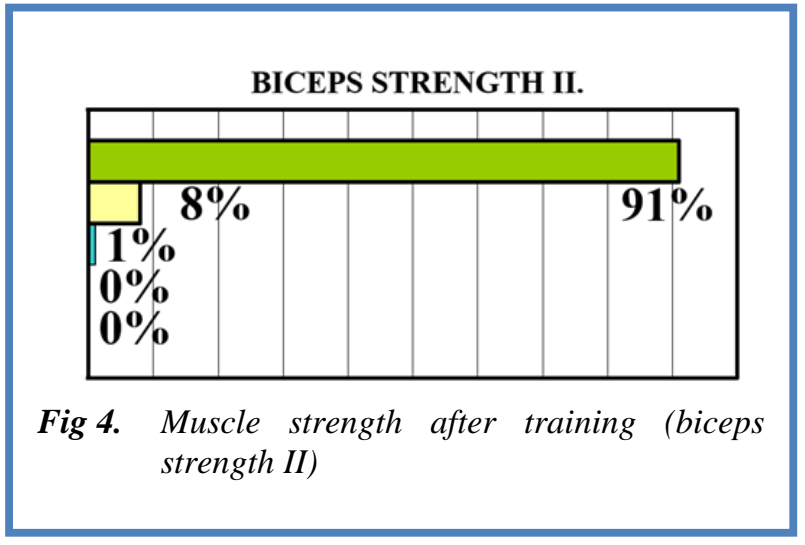

our study, anaerobic fitness was seen to increase after training, as measured by the surrogate of biceps muscle strength.

In conclusion, a well-trained and homogeneous group means greater safety for when they perform their tasks together. Having one element of the team fatiguing in a hostile environment may increase the risk of the group as a whole. This situation may slow down the whole group and affect final result. ${ }^{4-6}$ In our methodological approach, we obtained a team of soldiers with a highly homogenous set of physical capacities. ${ }^{7-9}$ A homogeneous team in terms of fitness can therefore increase responsiveness and preparedness in adapting to conditions of a hostile environment; such as an alpine could be. ${ }^{10,11}$

\section{List of acronyms}

ECG - electrocardiogram

EU - European Union

CaSTA - International Alpine Troup Championchips

\section{Authors contributions}

All named authors played a substantial role in the conception and/or study design, data acquisition and/or analysis, as well as drafting of the manuscri agree the

\begin{tabular}{|c|c|c|c|}
\hline \multicolumn{2}{|c|}{ Table 1. Hydration-dehydration characteristics of soldiers } \\
\hline $\begin{array}{c}\text { 60 Alpine } \\
\text { Soldiers }\end{array}$ & $\begin{array}{c}\text { First evaluation } \\
\text { The group is not } \\
\text { homogeneous } \\
\text { Hydration is low }\end{array}$ & $\begin{array}{c}\text { Last evaluation } \\
\text { The group is } \\
\text { homogeneous } \\
\text { Hydration is sufficient }\end{array}$ & $\begin{array}{c}\text { Mean value } \\
\text { of males aged more } \\
\text { than } 30 \text { years }\end{array}$ \\
\hline $\begin{array}{c}\text { Resistance } \\
\text { Rz/H }(\Omega / \mathrm{m})\end{array}$ & $\begin{array}{c}350+/-100 \\
\text { Low levels of water and } \\
\text { mineral salts }\end{array}$ & $\begin{array}{c}\text { Good levels of water } \\
\text { and mineral salts }\end{array}$ & \\
\hline $\begin{array}{c}\text { Conductance } \\
(\mathrm{Xc} / \mathrm{H}(\Omega / \mathrm{m}))\end{array}$ & $\begin{array}{c}\text { Low current conduction and } \\
\text { Low neuromuscular } \\
\text { conduction }\end{array}$ & $47+/-10$ & $>62 \%$ \\
\hline $\begin{array}{c}\text { Total Body } \\
\text { Water }(\%)\end{array}$ & $45+/-7$ & $54+/-6$ & \\
\hline
\end{tabular}


accountability for all aspects of accuracy and integrity of the work.

\section{Acknowledgments}

None

Funding No funding was obtained for this research.

\section{Conflict of Interest}

The authors declare they have no financial, personal, or other conflicts of interest.

\section{Ethical Publication Statement}

We confirm that we have read the Journal's position on issues involved in ethical publication and affirm that this report is consistent with those guidelines.

\section{Corresponding Author}

Paola V. Gigliotti, Department of Medicine, University of Perugia, Ospedale "Santa Maria della Misericordia", Italy; and Laboratory of Sport Physiology, San CandidoInnichen, Italy. ORCID iD: 0000-0002-0846-7444 Email: pao.gigliotti@gmail.com

\section{E-mails of co-authors}

AlexanderPiratinskij: apiratinskiy@yandex.ru ORCID iD: 0000-0002-8611-525X

Saadsaoud Foued: foued.saadsaoud@univ-msila.dz ORCID iD: 0000-0001-8228-4497

Igor Diemberger: igor.diemberger@unibo.it. ORCID iD: 0000-0002-3823-3809

Rezhna Adil Rasheed: rezhna.rashid@epu.edu.iq ORCID iD: 0000-0002-0846-7444

Giorgio Fanò-Illic: fanoillic@gmail.com

ORCID iD: 0000-0002-8753-5707

Francesco Coscia: francesco.coscia@ sabes.it ORCID iD: 0000-0003-1900-0302

\section{References}

1. Garber CE, Blissmer B, Deschenes MR, et al. American College of Sports Medicine Position Stand. Quantity and Quality of Exercise for Developing and Maintaining Cardiorespiratory, Musculoskeletal, and Neuromotor Fitness in Apparently Healthy Adults: Guidance for Prescribing Exercise. American College of Sports Medicine. Med Sci Sports Exerc 2011;43:1334-59. doi: 10.1249/MSS.0b013e318213fefb.

2. Coscia F, Parisi F, Gigliotti PV, et al. Capacità Fisiche e Addestramento Giornale di Medicina Militare Ed Direzione Generale della Sanità
Militare anno $155^{\circ}$ Fasc 1/2005 genn.-marzo 2005 Roma pp. 93-97.

3. Orciuoli V, Gigliotti PV, Parisi F, et al. Prove di efficienza fisica e prevenzione. Importanza della valutazione internistica completa in occasione della visita medica periodica Giornale di Medicina Militare Ed Direzione Generale della Sanità Militare anno $159^{\circ}$ Fasc 2/2009 maggio-agosto 2009 Roma, pp. 221-226.

4. Maupin D, Wills T, Orr R, Schram B. Fitness Profiles in Elite Tactical Units: A Critical Review. Int J Exerc Sci. 2018 Aug 1;11(3):1041-1062.

5. Maupin D, Robinson J, Wills T, et al. Profiling the metabolic fitness of a special operations police unit. J Occup Health. 2018 Sep 26;60(5): 356-360.

6. Dawes JJ, Orr RM, Flores RR, et al. A physical fitness profile of state highway patrol officers by gender and age. Ann Occup Environ Med. 2017 Jun 1;29:16. doi: 10.1186/s40557-017-0173-0.

7. Skorski S, Mujika I, Bosquet L. et al. The Temporal Relationship Between Exercise, Recovery Processes, and Changes in Performance. Int J Sports Physiol Perform. 2019 Sep 1;14(8):10151021.doi:10.1123/ijspp.2018-0668.

8. Ghanvatkar S, Kankanhalli A, Rajan V. User Models for Personalized Physical Activity Interventions: Scoping Review. JMIR Mhealth Uhealth. 2019 Jan 16;7(1):e11098. doi: 10.2196/11098.

9. Hovey R Examination of the Bosco Jump Test Thesis submitted to the Faculty of Graduate Studies and Research in Partial Fulfillment of the Requirements for the Degree of Kaster of Arts (Education) Department of Physical Education Faculty of Education Division of Graduate Studies and Research McGill University Montreal, Quebec, Canada July 1989

10. Gigliotti PV, Parisi F, Fedele P, et al. Studio di omogeneizzazione e mantenimento delle capacita' fisiche della $63^{\wedge}$ Compagnia del $6^{\wedge}$ reggimento Alpini impegnata al Sestriere. Giornale di Medicina Militare 2007 giugno;157(2): 305-317.

11. Cavicchioli A, Gigliotti PV, Coscia F. L'Attività fisica in montagna Rassegna dell'Esercito suppl. al n. 6/2004 di Rivista Militare, pp. 64-79.

Submission: February 5, 2020

Revision received: February 19, 2019

Acceptance: February 19, 2020 